\title{
Rapid and Simple Extraction Method for Volatile N-Nitrosamines in Meat Products
}

\author{
Mohammad Al-Kaseem*, Zaid Al-Assaf, Franswa Karabet
}

Department of Analytical and Food Chemistry, Faculty of Pharmacy, Damascus University, Damascus, Syria. Email: *mkaseem74@gmail.com

Received September $21^{\text {st }}, 2013$; revised October $22^{\text {nd }}, 2013$; accepted October $29^{\text {th }}, 2013$

Copyright (C) 2013 Mohammad Al-Kaseem et al. This is an open access article distributed under the Creative Commons Attribution License, which permits unrestricted use, distribution, and reproduction in any medium, provided the original work is properly cited.

\begin{abstract}
A new methodology for extraction, pre-concentration and analysis of volatile nitrosamines in meat-derived products was developed and compared with conventional methods (Distillation and two-step solid-phase extraction). The samples (canned sausages, cured meat, luncheon and smoked meat) were treated with an aqueous sodium hydroxide $(\mathrm{NaOH})$ by autoclaving at $121^{\circ} \mathrm{C}$ for $10 \mathrm{~min}$ and extracted by liquid-liquid extraction with dichloromethane, then the nitrosamines were pre-concentrated using activated silica. Then, gas chromatography coupled with flame ionization detector was used for the separation and determination of the different nitrosamines contained in a real sample and gas chromatography with mass spectrometry detection was used as the confirmation technique. The newly invented autoclaving method allowed the determination of nitrosamine compounds at trace levels with limit of detection ranged from 0.077 to $0.18 \mathrm{ppb}$ and quantitation limits were from 0.26 to $0.6 \mathrm{ppb}$ for all nitrosamines, and found to be superior to the conventional ones, yielding approximately about $10 \%$ - 20\% increasing in the recovery compared with the mean recovery obtained when applying conventional methods.
\end{abstract}

Keywords: GC-FID; N-Nitrosamines; LLE; Meat; Autoclave

\section{Introduction}

N-Nitrosamines (NAs), mainly N-nitrosodimethylamine (NDMA), and N-nitrosodiethylamine (NDEA) are receiving special attention, because they present high mutagenic and carcinogenic potential that can induce tumors in variety of organs, including the liver, lung, kidney, bladder, pancreas, esophagus and tongue depending on the species, but not in the skin, brain, colon or bone. For example, N-nitrosodimethylamine at the levels of 20 ppm can induce liver cancer in a human [1]. The International Agency for Research on Cancer (IARC) classified NDMA and NDEA as most carcinogenic to humans, and N-nitrosodi-n-butylamine (NDBA), N-nitrosopiperidine (NPIP) and N-nitrosopyrrolidine (NPYR) as possibly carcinogenic to humans [2,3]. In the diet, they occur as unintentional byproducts of food preparation, preservation and processing [4], although they can also occur in the environmental tobacco smoke [5], and may be formed endogenously within the human body [6]. These compounds are formed by the reaction of secondary amines

${ }^{*}$ Corresponding author. with nitrosating agents, such as nitrates or nitrites, which are commonly used in the manufacture of meat products [4-7]. For this reason, the use of these nitrosating agents for curing meat is strictly controlled in some countries [8]. Moreover, some known inhibitors of the nitrosation reaction, such as ascorbic acid, are used in the processing of several foods [9]. The determination of nitrosamines in food and water samples has been carried out by different analytical methods, including colorimetry [10,11], capillary electro-chromatography [12], micellar electrokinetic capillary chromatography [13], gas chromatography with flame ionization detection, nitrogen phosphorous detection, thermal energy detection, nitrogen chemiluminescence detection [14-17], and mass spectrometry detection [18-20], high-performance liquid chromatography with thermal energy analyzer, mass spectrometry and fluorescence detection $[21,22]$. The extraction of the nitrosamine from the complex food matrices and the cleanup of the extract have been the critical points of the sample preparation step, and several approaches are documented in the literatures, including distillation (steam or vacuum) [23-25], solvent extraction, [26] solid-phase 
extraction [27], solid-phase micro-extraction (SPME) [28], and supercritical fluid extraction [29].

This paper describes the development of a simple method for the extraction of volatile nitrosamines from meat products using sodium hydroxide to enhance the stability under autoclaving conditions and comparing the new method with the conventional procedures (vacuum distillation and two-step solid-phase extraction with Extrelut and Florisil sorbents).

\section{Methods}

\subsection{Samples}

All meat samples (10 samples of each of cured meat, sausage, luncheon, and smoked meat) were purchased from supermarkets in Damascus. The samples were crushed and mix with no addition of the fluid and then stored in $-20^{\circ} \mathrm{C}$ before analysis.

\subsection{Materials}

EPA 521 nitrosamine mix standard was purchased from Supleco (USA), this solution contained seven analytes at $2000 \mu \mathrm{g} / \mathrm{mL}$ of each: N-nitrosodimethylamine (NDMA), $\mathrm{N}$-nitrosomethylethylamine (NMEA), N-nitrosodiethylamine (NDEA), N nitrosopyrrolidine (NPYR), N-nitrosodin-propylamine (NDPA), N-nitrosopiperidine (NPIP) and N-nitrosodi-n-butylamine (NDBA). For sample preparation, sodium hydroxide, ethanol, Methanol, hexane, octane and dichloromethane (DCM) and Florisil were purchased from Sigma-Aldrich (USA). Florisil water sep-pak cartridges from Waters (Milford, MA, USA). Extrelut and Activated Silica Gel (silica gel 60 extra pure. 70 - 230 mesh) were obtained from Merck (Germany). All other chemicals (ascorbic acid, sulfanilic acid, sulfuric acid, anhydrous sodium sulfate and sodium chloride) used in this research were of analytical laboratory grade.

\subsection{Apparatus}

Pyrex tubes $(20 \mathrm{ml})$ with heat-stable Teflon-lined caps and glass column $(30 \mathrm{~cm} \times 1.5 \mathrm{~cm})$ were used. KudernaDanish (KD) concentrator was used for the concentration of organic solvents. Autoclave (Selecta, Spain, 4001757) and gas chromatograph equipped with a flame ionization detector controlled by computer running GC-Solution software (GC-2014, Shimadzu, Japan) and an optimaXLB Capillary Columns $(0.25 \mathrm{~mm}$ i.d. $30 \mathrm{~m}, 0.25 \mu \mathrm{m})$ from (MACHEREY-NAGEL GmbH \& Co) were used. Agilent gas chromatography 7890A equipped with mass selective detector MS 5975C controlled by computer running Agilent Chemstation software (Agilent Technologies, Madrid, Spain) for confirmation of the results. Local steam distillation device and glassware were used for sample preparation.

\subsection{Preparation of Nitrosamine Mix Standard}

A series of working standard solutions were prepared by appropriate dilution of the EPA 521 nitrosamine mix with dichloromethane and stored at $-20^{\circ} \mathrm{C}$ before use. From the primary stock solution $2000 \mu \mathrm{g} / \mathrm{mL}$ of each nitrosamine, a $1 / 200$ dilution was done to get $100 \mu \mathrm{g} / \mathrm{mL}$ secondary stock solution of each nitrosamine. Sequentially dilute secondary stock solution was performed to get standards titrating at $4,10,50,100,500,1000 \mu \mathrm{g} / \mathrm{L}$ in by taking the following volumes from secondary stock solution, $40 \mu 1,100 \mu 1,500 \mu 1,1000 \mu 1,5 \mathrm{~mL}, 10 \mathrm{~mL}$ in series of $100 \mathrm{~mL}$ volumetric flasks respectively, these solution kept in the absence of light.

\subsection{Analytical Conditions}

GC analysis was carried out using GC-2014 gas chromatograph equipped with flame ionization. (GC-FID) (Shimadzo Technologies, Japan). One microliter of the extracted solution sample was injected into optima-XLB Capillary Column $(30 \mathrm{~m} \times 0.25 \mathrm{~mm}$ I.D. $\times 0.25$ film thickness (df)). For the gas chromatograph separation of $\mathrm{N}$-nitrosamines, the injection port and detector temperature were kept at $250^{\circ} \mathrm{C}$ and $300^{\circ} \mathrm{C}$. The oven program was as follows: $40^{\circ} \mathrm{C}$, held for $3 \mathrm{~min}$; ramp to $100^{\circ} \mathrm{C}$ at $10^{\circ} \mathrm{C} / \mathrm{min}$, held isothermally for $1 \mathrm{~min}$; ramp to $250^{\circ} \mathrm{C}$ at $15^{\circ} \mathrm{C} / \mathrm{min}$, held isothermally at $250^{\circ} \mathrm{C}$ for $2 \mathrm{~min}$. The sample was injected in splitless mode; using an injection volume of $1 \mu \mathrm{l}$. Nitrogen was used as make-up gas. The purity of all gases used was greater than $99.999 \%$. The velocity of the helium carrier was $1 \mathrm{~mL} / \mathrm{min}$. GC-MS were carried out to confirmation of the results using an optima XLB column $(30 \mathrm{~m} \times 0.25 \mathrm{~mm}$ I.D. $\times 0.25$ film thickness (df) column with same conditions used in GCFID and the injector and transfer line temperature in GCMS were $240^{\circ} \mathrm{C}$ and $275^{\circ} \mathrm{C}$, respectively. The ion source temperature was $240^{\circ} \mathrm{C}$ and operated in positive electron ionization (EI) $70 \mathrm{eV}$ mode.

\subsection{Conditions for Autoclave Treatment}

In this study, half $\mathrm{ml}$ of the $\mathrm{N}$-nitrosamine Mix standard containing $50 \mu \mathrm{g} / \mathrm{L}$ of each nitrosamine was diluted with $10 \mathrm{~mL}$ of $0,0.5,1 \mathrm{~N}, 2 \mathrm{~N}$ aqueous sodium hydroxide and $10 \mathrm{mg}$ of ascorbic acid (Inhibitor of endogenous nitrosation) in $20 \mathrm{~mL}$ Pyrex tubes tightly capped and autoclaved at $121^{\circ} \mathrm{C}$ for 5, 10, $30 \mathrm{~min}$. After being allowed to stand at room temperature, the autoclaved solution was transferred to $50 \mathrm{~mL}$ separatory funnel. The tubes was rinsed twice with $5 \mathrm{~mL}$ of ethanol and then $10 \mathrm{~mL}$ of dichloromethane, and the rinsing solutions and $10 \mathrm{~mL}$ of $10 \%$ aqueous sodium chloride were combined with the origi- 
nal extract in the separatory funnel. After being shaken, the dichloromethane layer was collected, and the water layer was re-extracted with $10 \mathrm{ml}$ of dichloromethane. The dichloromethane extracts were combined, dried over anhydrous sodium sulfate and concentrated to approximately $0.5 \mathrm{~mL}$ using $\mathrm{KD}$ concentrator and nitrogen gas flow. The concentrate was loaded onto a silica gel column $(30 \mathrm{~cm} \times 1.5 \mathrm{~cm})$ (equilibrated with dichloromethane) and the column was eluted with $10 \mathrm{ml}$ of dichloromethane. After the addition of $100 \mu \mathrm{L}$ of octane (to prevent exsiccation of the solvent), the elute was concentrated to $1 \mathrm{~mL}$ using $\mathrm{KD}$ concentrator and nitrogen gas flow and analyzed by GC-FID using $1 \mu \mathrm{L}$ injection volume, and confirmatory analyses were performed on GC-MS.

\subsection{Extraction of N-Nitrosamine from Meat}

\subsubsection{Autoclave Treatment}

Approximately one gram of meat sample was placed in the Pyrex tube into which $10 \mathrm{~mL}$ of sodium hydroxide 1 $\mathrm{N}$ was poured. The tube was capped tightly and autoclaved at $121^{\circ} \mathrm{C}$ for 5,10 and $30 \mathrm{~min}$; dichloromethane extract was obtained by the procedure described for the standard solution in (Section 2.6). The individual extracts were analyzed by GC-FID, GC-MS as in the case of the standard solution (Section 2.5).

\subsubsection{Steam Distillation}

Extraction was done as described by Komarova and Velikanov (2000) [22]. A weighed portion (80 - $100 \mathrm{~g})$ of a meat reduced in a homogenizer was placed in a $500-\mathrm{mL}$ round-bottom flask connected with a steam generator and a condenser. Distilled water $(100-150 \mathrm{~mL}$ depending on the humidity of the foodstuff) and $0.1 \mathrm{~mL}$ of $50 \mathrm{ppb}$ solution of each nitrosamine were added to the foodstuff and stirred. Next, $10 \mathrm{~g}$ of sodium chloride, $10 \mathrm{~g}$ of sodium or magnesium sulfate, $5 \mathrm{~mL}$ of a $2 \%$ sulfanilic acid solution (to inhabit endogenous nitrosation), and $10 \mathrm{~mL}$ of a $1 \mathrm{~N}$ sulfuric acid solution were added, and N-nitrosamines were steam distilled off collecting $250 \mathrm{~mL}$ of the distillate. The distillate was transferred into a separatory funnel, and N-nitrosamines were extracted with dichloromethane five times (with portions of $10 \mathrm{~mL}$ each). Each portion of the extract was passed through a funnel with a red-ribbon paper filter filled with $5 \mathrm{~g}$ of anhydrous sodium sulfate. The filter was washed with $10 \mathrm{~mL}$ of the extractant. All portions of the extract were combined and condensate using $\mathrm{KD}$ to $1 \mathrm{ml}$ and analyzed using GCFID.

\subsubsection{Two-Step Solid-Phase Extraction}

Extraction of nitrosamines was performed using the same method as Yurchenko and Molder (2007) [31]. A twostep solid-phase extraction using Extrelut and Florisil sorbents was used for sample cleaning. Each sample (6.0 $\pm 1.0 \mathrm{~g}$ ) was minced and mixed with $0.1 \mathrm{~mol} \cdot \mathrm{L}^{-1} \mathrm{NaOH}$ $(6 \mathrm{~mL})$. For the first step, $6 \mathrm{~g}$ of Extrelut was placed at the bottom of the glass column $(30 \mathrm{~cm} \times 1.5 \mathrm{~cm})$ and wetted with $20 \mathrm{~mL}$ hexane/dichloromethane 40:60 (v:v). Then, the sample was eluted with two $20 \mathrm{~mL}$ portions of hexane/dichloromethane solution 40:60 (v: v). the eluate was collected in a $50 \mathrm{~mL}$ concentrator flask and evaporated under a nitrogen stream. During the second step, 1 $\mathrm{g}$ of Florisil was placed at the bottom of the Florisil cartridge $(6.5 \mathrm{~cm} \times 1.3 \mathrm{~cm})$ and wetted with $6 \mathrm{~mL}$ dichloromethane/methanol 95:5 (v:v). Then the sample solution was eluted with $6 \mathrm{~mL}$ dichloromethane/methanol solution 95:5 (v: v). the solution was evaporated under a nitrogen stream to about $1 \mathrm{~mL}$. The prepared solution was transferred to the GC auto sampler vial. Extractions were performed in triplicate [30].

\section{Results and Discussion}

\subsection{Optimization of Conditions for Autoclave Treatment}

Figure 1 shows a chromatogram of the $\mathrm{N}$-nitrosamines standard solution obtained by GC-FID. The total recovery of nitrosamine for the autoclave treatment in water ranged from $61.1 \%$ to $98 \%$ depending on the heating period as shown in Table 1. This indicates that N-nitrosamines remained almost stable during the autoclave treatment because of the stability of N-nitrosamines under the alkaline conditions and difficulty to destroy them under these conditions [31], however, the total recovery of N-nitrosamines slightly decreased as the $\mathrm{NaOH}$ concentration increased or the heating period elongated. To clarify the reason for the decrease in the total N-nitrosamine recovery, the volatile nitrosamines in Figure 1 were analyzed and the results are shown in Table 2.

The recoveries of some $\mathrm{N}$-nitrosamines with rather short retention times such NDMA and NDEA were satisfactory under any conditions. In contrast, the decrease in the recovery was notable for the peaks with much longer retention times as the $\mathrm{NaOH}$ concentration increased or the heating period became longer. Since NPYR and NPIP giving longer retention times that, the decrease in the total N-nitrosamines recovery would result from the instability under the conditions of high $\mathrm{NaOH}$ concentration and lasted heating at $121^{\circ} \mathrm{C}$. Consequently, it was proposed that samples for $\mathrm{N}$-nitrosamines analysis should be treated with $1 \mathrm{~N} \mathrm{NaOH}$ for 10 $\min$.

\subsection{Efficacy of Autoclave Treatment for Extraction of N-Nitrosamines from Meat}

Table 3 shows the peak areas and total peak areas of Nnitrosamines for all extraction procedures, the peak areas 


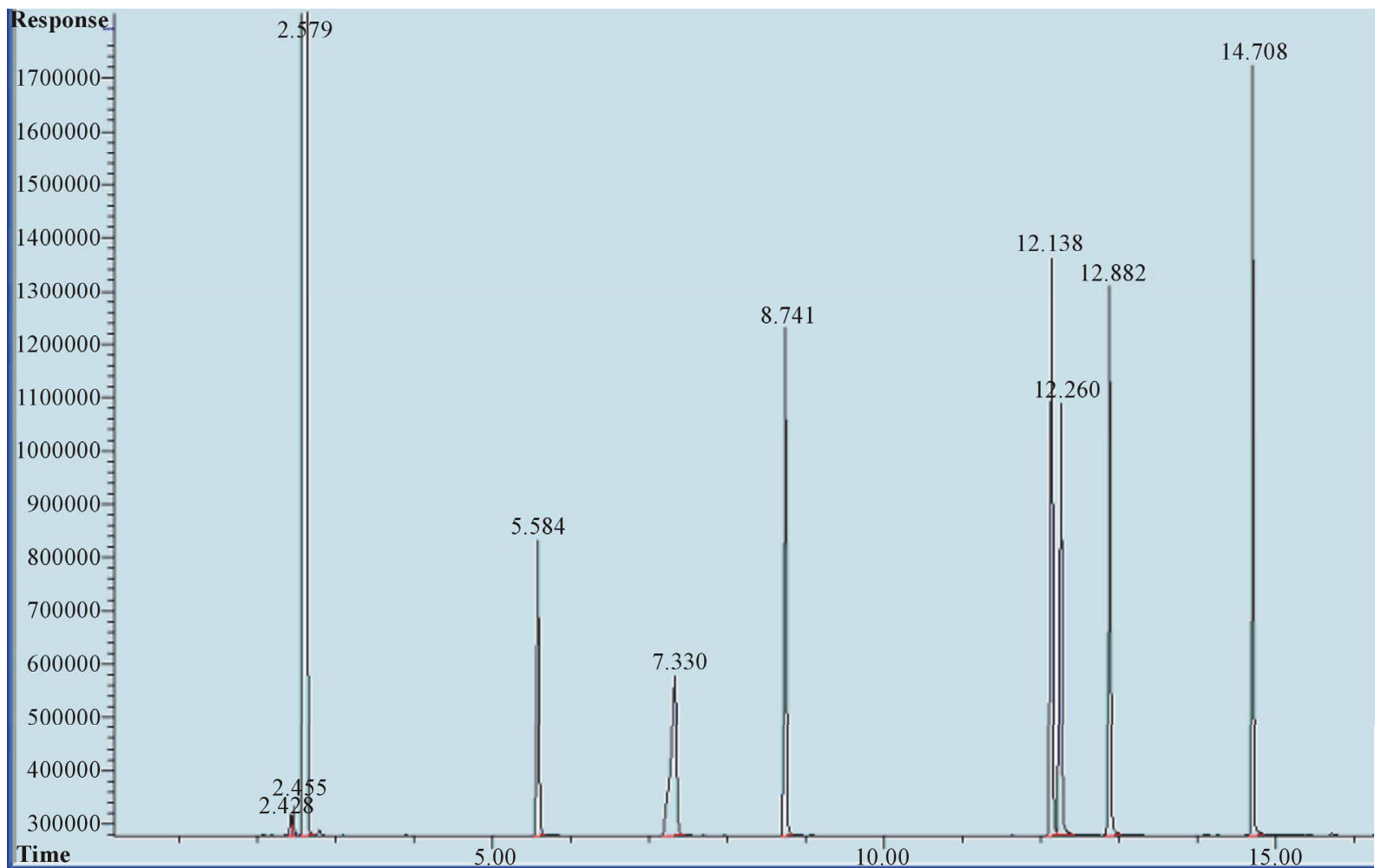

Figure 1. Chromatogram of $50 \mu \mathrm{g} / \mathrm{L}$ of $\mathrm{N}$-nitrosamine mix (GC-FID).

Table 1. Effect of alkali concentration and autoclaving times on total recovery of $\mathbf{N}$-nitrosamine.

\begin{tabular}{|c|c|c|c|c|c|c|}
\hline \multirow{3}{*}{ Alkali concentration } & \multicolumn{6}{|c|}{ Autoclaving time (min) } \\
\hline & \multicolumn{2}{|c|}{5} & \multicolumn{2}{|c|}{10} & \multicolumn{2}{|c|}{30} \\
\hline & Recovery (\%) & RSD (\%) & Recovery (\%) & $\operatorname{RSD}(\%)$ & Recovery (\%) & $\operatorname{RSD}(\%)$ \\
\hline $0 \mathrm{~N} \mathrm{NaOH}$ (water) & 61.1 & 6.8 & 76 & 8.9 & 62.7 & 9.24 \\
\hline $0.5 \mathrm{~N} \mathrm{NaOH}$ & 85.9 & 2.7 & 97.8 & 4.3 & 87.9 & 8.5 \\
\hline $1 \mathrm{~N} \mathrm{NaOH}$ & 88.4 & 2.8 & 98.1 & 1.05 & 88.4 & 3.1 \\
\hline $2 \mathrm{~N} \mathrm{NaOH}$ & 87.2 & 5.6 & 87.6 & 4.6 & 88.5 & 6.4 \\
\hline
\end{tabular}

Each value represents mean (S) and relative standard deviation (RSD) in three experiments.

Table 2. Effect of alkali concentration and autoclaving times on recovery of N-nitrosamines.

\begin{tabular}{|c|c|c|c|c|c|c|c|c|c|}
\hline \multirow{3}{*}{ NA } & \multicolumn{9}{|c|}{ Autoclaving time (min) } \\
\hline & $5 \mathrm{~min}$ & $10 \mathrm{~min}$ & $15 \mathrm{~min}$ & $5 \mathrm{~min}$ & $10 \mathrm{~min}$ & $15 \mathrm{~min}$ & $5 \mathrm{~min}$ & $10 \mathrm{~min}$ & $15 \mathrm{~min}$ \\
\hline & \multicolumn{3}{|c|}{$\begin{array}{l}\text { With } \mathrm{NaOH} 0.5 \mathrm{~N} \\
\text { (Recovery \%) }\end{array}$} & \multicolumn{3}{|c|}{$\begin{array}{l}\text { With NaOH } 1 \mathrm{~N} \\
\text { (Recovery \%) }\end{array}$} & \multicolumn{3}{|c|}{$\begin{array}{l}\text { With } \mathrm{NaOH} 2 \mathrm{~N} \\
\text { (Recovery \%) }\end{array}$} \\
\hline NDMA & 80.0 & 89.7 & 88.9 & 90.2 & 105.5 & 93.7 & 88.4 & 80.7 & 80.6 \\
\hline NMEA & 88 & 89 & 76 & 67 & 89 & 89 & 76 & 73 & 89 \\
\hline NDEA & 85.6 & 87.8 & 85.6 & 80.1 & 102.3 & 91.4 & 88.5 & 79.3 & 80.5 \\
\hline NPYR & 77.1 & 79.0 & 77.1 & 80.2 & 99.1 & 90.2 & 86.9 & 75.3 & 70.3 \\
\hline NDPA & 80.6 & 86.3 & 76.4 & 80.3 & 98.5 & 93.8 & 86.4 & 77.1 & 83.6 \\
\hline NPIP & 73.2 & 80.2 & 75.3 & 86.3 & 99.3 & 88.9 & 83.4 & 77.3 & 86.1 \\
\hline NDBA & 69.9 & 73.7 & 69.3 & 80.3 & 92.1 & 88.3 & 85.3 & 82.9 & 71.6 \\
\hline
\end{tabular}

Each value represent mean of three experiments, N; normality, N-nitrosodimethylamine (NDMA), N-nitrosomethylethylamine (NMEA), N-nitrosodiethylamine (NDEA), N nitrosopyrrolidine (NPYR), N-nitrosodin-propylamine (NDPA), N-nitrosopiperidine (NPIP) and N-nitrosodi-n-butylamine (NDBA). 
Table 3. Determination of N-nitrosamines with and without autoclave treatment, and with conventional methods.

\begin{tabular}{cccccccccc}
\hline \multirow{2}{*}{ NAs } & \multirow{2}{*}{$\begin{array}{c}\mathrm{RT} \\
(\mathrm{min})\end{array}$} & \multicolumn{2}{c}{ With autoclave treatment } & \multicolumn{2}{c}{ Without autoclave treatment } & \multicolumn{3}{c}{ Distillation method } & \multicolumn{3}{c}{ Two step solid phase extraction } \\
\cline { 3 - 9 } & Area & Relative ratio & Area & $\mathrm{RV}^{*}$ & Area & $\mathrm{RV}^{*}$ & Area $^{*}$ & $\mathrm{RV}^{*}$ \\
\hline NDMA & 5.617 & 203348 & 0.08 & 103456 & 0.51 & 120087 & 0.59 & 180323 & 0.88 \\
NMEA & 7.344 & 287513 & 0.113 & 123456 & 0.43 & 160000 & 0.55 & 247909 & 0.86 \\
NDEA & 8.733 & 353106 & 0.139 & 201345 & 0.57 & 98000 & 0.27 & 314876 & 0.89 \\
NPYR & 12.104 & 442116 & 0.175 & 286776 & 0.65 & 121564 & 0.27 & 399887 & 0.90 \\
NDPA & 12.224 & 355971 & 0.14 & 173456 & 0.49 & 123546 & 0.34 & 291006 & 0.81 \\
NPIP & 12.853 & 400387 & 0.158 & 127999 & 0.32 & 259099 & 0.64 & 328987 & 0.82 \\
NDBA & 14.681 & 483347 & 0.191 & 254888 & 0.53 & 178988 & 0.37 & 393000 & 0.81 \\
total & & 2525788 & 1 & 1271376 & & 1061284 & & 2155988 & \\
\hline
\end{tabular}

Relative ratio ${ }^{*}$ area/total area, $\mathrm{RV}^{*}$ : peak area as the percentages of that of the autoclave treatment, NAs: nitrosamines, RT: retention time.

after the conventional treatments were shown as the percentages of the peak areas corresponding of autoclave treatment. All N-nitrosamines tested were detected after autoclaving. The peaks of N-nitrosamines were sharp and completely separated, and there is an increasing of the recovery (expressed as peak area) after autoclave treatment compared with the same sample when extracted without an autoclaving, or by conventional methods. Obviously, the relative percentage of peak area for each nitrosamine (Table 3) under autoclaving conditions was as twice as that of extraction without autoclaving or by distillation, and it was about $10 \%-20 \%$ more than that of the two-step solid-phase extraction.

\subsection{Method Validation}

The new method was validated to demonstrate that it is suitable for its intended purpose by the standard procedure to evaluate adequate validation characteristics [30, 32]. Retention times of selected N-nitrosamines was determined by using standard solutions of each nitrosamine, and the confirmation was performed using GC-MS. Figure 1 shows the chromatogram obtained by GC-FID of $50 \mathrm{ppb}$ (part per billion) standard solution of each $\mathrm{N}$ nitrosamines. Figure 2 shows the chromatogram obtained by unspiked meat sample. Table 4 shows the confirmation results of seven nitrosamines obtained when analyzing the same solution and identifying the retention times using GC-MS. In order to examine the linearity a series of working standard solutions at the concentrations of $4,10,50,100,500,1000 \mu \mathrm{g} / \mathrm{L}$ of each N-nitrosamine were prepared and analyzed under the selected chromatographic and flame ionization detector conditions. The linear equations, linear ranges and correlation coefficients for the seven nitrosamines are shown in Table 4. The limits of quantification with a signal-to-noise ratio of 10 for the seven nitrosamines were from 0.26 to $0.6 \mathrm{ppb}$ with limits of detection with a signal-to-noise ratio of 3 for the seven nitrosamines were from 0.077 to $0.18 \mathrm{ppb}$.
The recovery and precision experiments were conducted by spiking different blank samples at three spiking levels of $1,5,10 \mu \mathrm{g} / \mathrm{L}$, six replicates at each level, the mean recoveries were from $89 \%-105.5 \%$ with the relative standard deviations (RSDs) from $2.8 \%$ to $4.4 \%$.

\subsection{Sample Results}

Meat samples were treated with $1 \mathrm{~N} \mathrm{NaOH}$ for $10 \mathrm{~min}$ in autoclaved conditions and then analyzed by GC-FID and the results are shown in Table 5. The results of 40 samples of different meat products which examined for the test of the extraction procedure shows the presence of some volatile nitrosamine in all different products, and the absence of NDEA, NDPA, and NDBA in all the sample tested which may related to the presence of these three nitrosamines in low amounts which may below under the quantitation limit of our procedure, or the real absence of these nitrosamine in the sample tested. Statistically when applying (PASW Statistics 18) one way ANOVA test for statistical comparisons between the means of sum of seven nitrosamines in meat samples, there was significant difference $(p>0.05)$ which may related to the low number of different samples, or because that some of tested samples are commonly preserved by nitrite salts (sausages and luncheon) which contributing in nitrosamine formation and the effect of processing (smoking) in the formation of these carcinogenic compounds in smoked meat.

\section{Conclusion}

It was included in this paper that the extent of recovery of N-nitrosamines from the meat products was highly dependent on the extraction conditions, and it was concluded that extraction recovery could be increased when adopting the autoclave conditions and sodium hydroxide to increase the stability of volatile nitrosamine, and adding ascorbic acid to inhabit endogenous nitrosation which may occur during extraction. We recommend the newly 


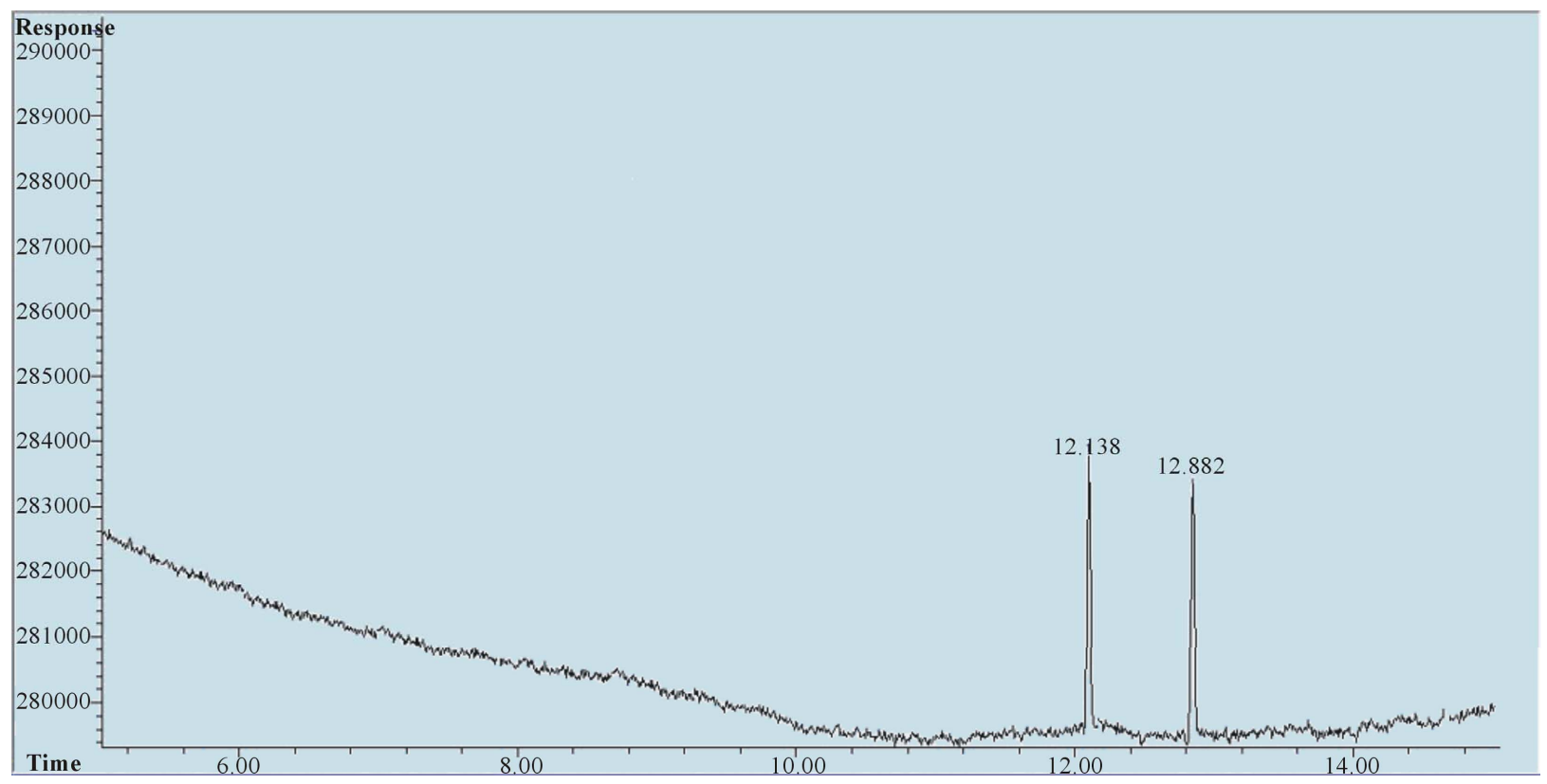

Figure 2. Chromatogram of unspiked meat sample.

Table 4. Linear equations, linear ranges and correlation coefficients of seven volatile nitrosamines.

\begin{tabular}{cccccccc}
\hline N-nitrosamine & $\begin{array}{c}\text { RT }^{*} \\
\text { GC-FID }\end{array}$ & $\begin{array}{c}\text { Confirmation RT } \\
\text { GC-MS }\end{array}$ & Linear equation & $\begin{array}{c}\text { Linear range } \\
\mu \mathrm{g} / \mathrm{L}\end{array}$ & $\begin{array}{c}\text { Correlation } \\
\text { coefficients }\end{array}$ & $\begin{array}{c}\text { LOQ } \\
\mu \mathrm{g} / \mathrm{kg}\end{array}$ & $\begin{array}{c}\text { LOD } \\
\mu \mathrm{g} / \mathrm{kg}\end{array}$ \\
\hline NDMA & 5.617 & 5.617 & $\mathrm{y}=4161.7 \mathrm{x}-9274.8$ & $0.6-500$ & 0.9997 & 0.6 & 0.18 \\
NMEA & 7.344 & 7.344 & $\mathrm{y}=5816.1 \mathrm{x}-14015$ & $0.43-500$ & 0.9994 & 0.43 & 0.13 \\
NDEA & 8.733 & 8.733 & $\mathrm{y}=7095.3 \mathrm{x}-13214$ & $0.33-500$ & 0.9996 & 0.33 & 0.1 \\
NPYR & 12.104 & 12.104 & $\mathrm{y}=8699.3 \mathrm{x}-8839.9$ & $0.26-500$ & 0.9995 & 0.26 & 0.08 \\
NDPA & 12.224 & 12.224 & $\mathrm{y}=6674.6 \mathrm{x}-3555.2$ & $0.25-500$ & 0.9981 & 0.25 & 0.077 \\
NPIP & 12.853 & 12.853 & $\mathrm{y}=7992.3 \mathrm{x}-141000$ & $0.34-500$ & 0.9995 & 0.34 & 0.105 \\
NDBA & 14.681 & 14.681 & $\mathrm{y}=9805.1 \mathrm{x}-16361$ & $0.30-500$ & 0.9998 & 0.309 & 0.093 \\
\hline
\end{tabular}

$\mathrm{RT}^{*}$ : retention time (minutes), GC-FID: gas chromatography-flame ionization detection, LOQ: limit of quantitation, LOD: limit of detection.

Table 5. Results on nitrosamine results in meat samples.

\begin{tabular}{|c|c|c|c|c|c|c|c|c|}
\hline \multirow{2}{*}{ products } & \multirow{2}{*}{ No. of samples } & \multicolumn{6}{|c|}{ Mean concentration $(\mathrm{n}=3)$ of $\mathrm{N}$-nitrosamine $\mu \mathrm{g} / \mathrm{kg}$} & \multirow{2}{*}{ Sum of seven N-nitrosamine $\mu \mathrm{g} / \mathrm{kg}$} \\
\hline & & NDMA & NDEA & NDPA & NDBA & NPYR & NPIP & \\
\hline Sausage & 10 & $\mathrm{nd}^{*}$ & $\mathrm{nd}^{*}$ & $\mathrm{nd}^{*}$ & $\mathrm{nd}^{*}$ & 2.78 & 2.98 & 4.76 \\
\hline Cured Meat & 10 & $\mathrm{nd}^{*}$ & $\mathrm{nd}^{*}$ & $\mathrm{nd}^{*}$ & $\mathrm{nd}^{*}$ & 3.2 & nd & 3.20 \\
\hline Luncheon & 10 & $\mathrm{nd}^{*}$ & $\mathrm{nd}^{*}$ & $\mathrm{nd}^{*}$ & $\mathrm{nd}^{*}$ & 2.60 & nd & 2.60 \\
\hline Smoked meat & 10 & $\mathrm{nd}^{*}$ & $\mathrm{nd}^{*}$ & $\mathrm{nd}^{*}$ & $\mathrm{nd}^{*}$ & 3.70 & 2.60 & 6.60 \\
\hline
\end{tabular}

nd ${ }^{*}:$ not detected.

invented method which employs an autoclave for the estimation of volatile N-nitrosamines contents in meat products.

\section{REFERENCES}

[1] M. W. Byun, H. J. Ahn, J. H. Kim, J. W. Lee, H. S. Yook and S. B. Han, "Determination of Volatile N-Nitrosamines in Irradiated Fermented Sausage by Gas Chromatog- raphy Coupled to a Thermal Energy Analyzer," Journal of Chromatography A, Vol. 1054, No. 1-2, 2004, pp. 403407.

[2] IARC Monographs on the Evaluation of Carcinogenic Risks to Humans, "Monographs Programme Finds Smokeless Tobacco Is Carcinogenic to Humans," International Agency for Research on Cancer, 2004.

[3] D. Kocak, M. Z. Ozel, F. Gogus, J. F. Hamilton and A. C. Lewis, "Determination of Volatile Nitrosamines in 
Grilled Lamb and Vegetables Using Comprehensive Gas Chromatography-Nitrogen Chemiluminescence Detection," Food Chemistry, Vol. 135, No. 4, 2012, pp. 22152220. http://dx.doi.org/10.1016/j.foodchem.2012.07.002

[4] N. Campillo, P. Viñas, N. C. Martinez and M. H. Córdoba, "Determination of Volatile Nitrosamines in Meat Products by Microwave-Assisted Extraction and Dispersive Liquid-Liquid Micro-Extraction Coupled to Gas Chromatography-Mass Spectrometry," Journal of Chromatography A, Vol. 1218, No. 14, 2011, pp. 1815-1821. http://dx.doi.org/10.1016/j.chroma.2011.02.010

[5] W. G. Lin, F. Wei, F. N. Gu, X. Dong, L. Gao, T. T. Zhuang, M. B. Yue and J.H. Zhu, "Adsorption of Nitrosamines by Mesoporous Zeolite," Journal of Colloid and Interface Science, Vol. 348, No. 2, 2010, pp. 621-627. http://dx.doi.org/10.1016/j.jcis.2010.05.012

[6] R. Andrade, F. G. Reyes and S. Rath, "A Method for the Determination of Volatile N-Nitrosamines in Food by HS-SPME-GC-TEA," Food Chemistry, Vol. 91, No. 1, 2005, pp. 173-179.

http://dx.doi.org/10.1016/j.foodchem.2004.08.015

[7] B. J. Sanchez, E. Ballesteros and M. Gallego, "Automatic Screening Method for the Pre-Concentration and Determination of N-Nitrosamines in Water," Talanta, Vol. 73, No. 3, 2007, pp. 498-504.

http://dx.doi.org/10.1016/j.talanta.2007.04.007

[8] K. O. Honikel, "The Use and Control of Nitrate and Nitrite for the Processing of Meat Products," Meat Science, Vol. 78, No. 1-2, 2008, pp. 68-76.

http://dx.doi.org/10.1016/j.meatsci.2007.05.030

[9] R. A. Scanlan, "Encyclopedia of Food and Nutrition," Elsevier, 2003, pp. 4142-4147. http://dx.doi.org/10.1016/B0-12-227055-X/00831-2

[10] M. J. Dennis, P. E. Key, T. Papworth, M. Pointer and R. C. Massey, "The Determination of Nitrate and Nitrite in Cured Meat by HPLC/UV," Food Additives and Contaminants, Vol. 7, No. 4, 1990, pp. 455-461. http://dx.doi.org/10.1080/02652039009373908

[11] F. E. Okieimana, E. O. Akintola, T. C. A. Anucha and M. M. Ajibola, "Determination of Total Level of Nitrosamine Contamination of Some Consumer Products in Nigeria," International Journal of Environmental Analytical Chemistry, Vol. 21, No. 4, 1985, pp. 261-266. http://dx.doi.org/10.1080/03067318508077067

[12] M. T. Matyska, J. J. Pesek and L. Yang, "Screening method for Determining the Presence of N-Nitrosodiethanolamine in Cosmetics by Open-Tubular Capillary Electrochromatography," Journal of Chromatography A, Vol. 887 , No. 1-2, 2000, pp. 487-503. http://dx.doi.org/10.1016/S0021-9673(00)00451-9

[13] M. Qiang, X. H. Wei, W. Chao, B. Hua, X. G. Cheng, S. Ning, X. L. Yan and W. J. Bing, "Determination of Ten Volatile Nitrosamines in Cosmetics by Gas Chromatography Tandem Mass Spectrometry," Chinese Journal of Analytical Chemistry, Vol. 39, No. 8, 2011, pp. 12011207. http://dx.doi.org/10.1016/S1872-2040(10)60466-5

[14] J. E. Grebel and H. I. Suffet, "Nitrogen-Phosphorus Detection and Nitrogen Chemiluminescence Detection of Volatile Nitrosamines in Water Matrices: Optimization and Performance Comparison," Journal of Chromatography A, Vol. 1175, No. 1, 2007, pp. 141-144. http://dx.doi.org/10.1016/j.chroma.2007.09.073

[15] M. Z. Ozel, F. Gongus, S. Yagci, J. F. Hamilton and A. C. Lewis, "Determination of Volatile Nitrosamines in Various Meat Products Using Comprehensive Gas Chromatography-Nitrogen Chemiluminescence Detection," Food and Chemical Toxicology, Vol. 48, No. 11, 2010, pp. 3268-3273. http://dx.doi.org/10.1016/j.fct.2010.08.036

[16] B. Hfiger and R. Niessner, "Determination of N-Nitrosomethylaniline and Methylaniline in the Gas Phase," Microchimica Acta, Vol. 122, No. 1-2, 1996, pp. 35-44. http://dx.doi.org/10.1007/BF01252403

[17] J. A. Incavo and M. A. Schafer, "Simplified Method for the Determination of N-Nitrosamines in Rubber Vulcanizates," Analytica Chimica Acta, Vol. 557, No. 1-2, 2006, pp. 256-261. http://dx.doi.org/10.1016/j.aca.2005.10.018

[18] D. Tsikas, "Methods of Quantitative Analysis of the Nitric Oxide Metabolites Nitrite and Nitrate in Human Biological Fluids," Free Radical Research, Vol. 39, No. 8, 2005, pp. 797-815. http://dx.doi.org/10.1080/10715760500053651

[19] J. W. Dallinga, D. M. Pachen, A. H. Lousberg, J. A. Van Geel, G. M. Houben, R. W. Stockburgger, J. M. Maanen and J. C. Kleinjans, "Volatile N-Nitrosamines in Gastric Juice of Patients with Various Conditions of the Gastrointestinal Tract Determined by Gas ChromatographyMass Spectrometry and Related to Intragastic $\mathrm{pH}$ and $\mathrm{Ni}$ trate and Nitrite Levels," Cancer Letters, Vol. 124, No. 2, 1998, pp. 119-125. http://dx.doi.org/10.1016/S0304-3835(97)00467-9

[20] Y. Xia, J. E. McGuffey, S. Bhattacharyya, B. Sellergren, E. Yilmaz and L. Wang, "Analysis of the Tobacco-Specific Nitrosamine 4-(Methylnitrosamino)-1-(3-Pyridyl)-1Butanol in Urine by Extraction on a Molecularly Imprinted Polymer Column and Liquid Chromatography/ Atmospheric Pressure Ionization Tandem Mass Spectrometry," Analytical Chemistry, Vol. 77, No. 23, 2005, pp. 7639-7645. http://dx.doi.org/10.1021/ac058027u

[21] G. Bellec, M. C. Cauvin, K. L. Calve, Y. Dreano, H. Gouerou, J. F. Menez and F. Berthou, "Analysis of N-Nitrosamines by High-Performance Liquid Chromatography with Post-Column Photohydrolysis and Colorimetric Detection," Journal of Chromatography A, Vol. 727, No. 1, 1996, pp. 83-92. http://dx.doi.org/10.1016/0021-9673(95)01073-4

[22] N. V. Komarova and A. A. Velikanov, "Determination of Volatile N-Nitrosamines in Food by High-Performance Liquid Chromatography with Fluorescence Detection," Journal of Analytical Chemistry, Vol. 56, No. 4, 2001, pp. 359-363. http://dx.doi.org/10.1023/A:1016652213062

[23] Association of Official Analytical Chemists, "N-Nitrosamines (Volatile) in Fried Bacon. Mineral Oil Vacuum Distillation-Thermal Energy Analyzer Method," No. 982.22, Official Methods of Analysis, 15th Edition, 1990.

[24] E. L. Greenfield, W. J. Smith and A. J. Malanovski, "Mineral Oil Vacuum Distillation for Nitrosamines in Fried Bacon, with Thermal Energy Analyser," Journal of the Association Official Analytical Chemists, Vol. 65, No. 6, 1982, pp. 1319-1332. 
[25] G. M. Telling, T. A. Bryce and J. J. Althorpe, "Use of Vacuum Distillation and Gas Chromatography-Mass Spectrometry for Determining Low Levels of Volatile Nitrosamines in Meat Products," Journal of Agricultural and Food Chemistry, Vol. 19, No. 5, 1971, pp. 937-940. http://dx.doi.org/10.1021/if60177a011

[26] J. Nawrocki and P. Andrzejewski, "Nitrosamines and Water," Journal of Hazardous Materials, Vol. 189, No. 1-2, 2011, pp. 1-18. http://dx.doi.org/10.1016/j.jhazmat.2011.02.005

[27] S. Raoul, E. Gremaud, H. Biaudet and R. Tureski, "Rapid Solid-Phase Extraction Method for the Detection of Volatile Nitrosoamines in Food," Journal of Agricultural and Food Chemistry, Vol. 45, No. 12, 1997, pp. 4706-4713. http://dx.doi.org/10.1021/jf970232q

[28] S. Ventanas, D. Martín, M. Estévez and J. Ruiz, "Analysis of Volatile Nitrosamines from a Model System Using SPME-DED at Different Temperatures and Times of Ex- traction," Food Chemistry, Vol. 99, No. 4, 2006, pp. 842850. http://dx.doi.org/10.1016/j.foodchem.2005.08.035

[29] W. Fiddler and J. W. Pensabene, "Supercritical Fluid Extraction of Volatile N-Nitrosamines in Fried Bacon and Its Drippings: Method Comparison," Journal of AOAC International, Vol. 79, No. 4, 1996, pp. 895-901.

[30] International Conference on Harmonization, "Validation of Analytical Procedure, Text and Methodology Q2 (R1)," 2005 IFPMA, Geneva, Switzerland.

[31] M. L. Nollet and F. Toldra, "Handbook of Processed Meats and Poultry Analysis," In: S. Rath and F. G. R. Reyes, Nitrosamines, Taylor \& Francis Group, An Informa Business, New York, 2009, p. 688.

[32] S. Yurchenko and U. Molder, "The Occurrence of Volatile N-Nitrosamines in Estonian Meat Products," Food Chemistry, Vol. 100, No. 4, 2007, pp. 1713-1721. http://dx.doi.org/10.1016/j.foodchem.2005.10.017 